\title{
Juvenile Delinquency and Differential Association Theory
}

\section{Munirah Abdullah Alduraywish}

Teaching Assistant at Social Department, Art Collage, King Saud University, Riyadh, Saudi Arabia

Email: maldraiwish@ksu.edu.sa

How to cite this paper: Alduraywish, M A. (2021). Juvenile Delinquency and Differential Association Theory. Advances in Applied Sociology, 11, 341-349. https://doi.org/10.4236/aasoci.2021.118031

Received: July 7, 2021

Accepted: August 1, 2021

Published: August 4, 2021

Copyright ( 2021 by author(s) and Scientific Research Publishing Inc. This work is licensed under the Creative Commons Attribution-NonCommercial International License (CC BY-NC 4.0).

http://creativecommons.org/licenses/by-nc/4.0/ (c) (i) (8) Open Access

\begin{abstract}
In this research paper, the researcher used a qualitative approach which is data collection in the juvenile delinquency topic, and differential association theory which is the most prominent form of social learning theory. The researcher hypothesized that there is a linkage between having deviant parents and becoming a criminal as well as having deviant friends and becoming a criminal. In this paper, the researcher found that the effect of deviant peer groups and deviant parent during adolescence is quite similar. Both peer groups and parents have an important position in the teenager's life; the researcher also found that slum neighborhoods, fragile personality, and poverty play critical roles in delinquency.
\end{abstract}

\section{Keywords}

Adolescent, Antisocial Behavior, Criminal Behavior, Deviant, Network of Affiliation, Parents, Peer Groups, Social Network

\section{Introduction}

Juvenile delinquency is one of the most complicated topics in criminal justice and sociology. There are researchers from different fields that have been trying to discover the significant reason for the issue; if it's sociological, physical or psychological. This paper examines the influence of deviant parent and peer groups of teenagers between $12-17$ years. Proposed here is a study to explore if there is a strong correlation between being delinquent and interaction with deviant parent and peer groups. The study will identify if the parents have a great role to help reduce juvenile delinquency.

\section{Theory}

There are social and intellectual conditions that impact differential association 
theory. The first social influence on Sutherland sight was when Chicago school scholars confirming the conception of the crimes are portions of sociological field more than biological or psychological fields. The Great Depression also impacted Sutherland thoughts when he observed how people reacted differently during that time, so he decided that crimes and criminal behavior are results of condition opportunity and values rather than feeble-mindedness. In addition, prohibition and the criminalization of drug use impacts Sutherland analyses of criminal behavior, Williams and McShane, 2013 stated: "individuals who engage in behavior that was not criminal at one point could become criminals engaging in the same behavior subsequent to the mere passage of law" (p. 65). Later, Sutherland came up with the idea of legal codes which means that criminal behavior is evaluated by society based on adherence to the law (Williams and McShane, 2013: p. 65). Moreover, in Criminological Theory, Williams and McShane, 2013 stated: "the main intellectual influence on Sutherland thinking came from the members of the Chicago school, especially the influence of symbolic interactions materials" (p. 66).

Beside the influence of symbolic interactionism, Sutherland was also influenced by ecological and cultural transmission theory and culture conflict theory. Scientifically, culture conflict was established by Sutherland and Sellin as orienting strategy for criminology. Sutherland also was concerned about the examination of statistical data and life history, Williams and McShane, 2013 indicate: "the life history approach was practiced by Sutherland in collection of case histories from incarcerated immigrants and in a series of interviews and contacts with a professional thief beginning in about 1930" (p. 66). Moreover, Sutherland was attracted in the object of moving on immigration, and the high rates of crime of in the center of Chicago city. Furthermore, first use of the term "differential association" was when Sutherland explains how the thieves associate with each other by creating their own values and culture, and the goal of created this term was to build theory stand on rigorous scientific criteria. Sutherland was influenced by the critique of criminology written by Jerome Michael and Mortimer J. Adler in 1933. Sutherland theory was reviewed in three copies and the last version was in 1947 (Williams and McShane, 2013: pp. 66-67). Finally, as we stated prior that Sutherland was concerned about crime rates and how persons became criminals, he also explained criminal behavior, according to Williams and McShane, 2013: "he was able to make sense of both varying crime rates in society (the culture conflict approach) and the process by which individuals became criminal (the symbolic interactional approach). Within this context, Sutherland formulated a theory that was an attempt to explain both individual criminal behavior and the variation in group (societal) rates of crime. He had to take into account that: 1) criminal behavior is not necessarily different from conventional behavior, 2) values are important in determining behavior, and 3) Certain locations and people are more crime prone than others" (p. 67).

In addition, one of the most prominent forms of social learning theory is the differential association theory which this paper will focus on. The principles of 
differential association theory are:

1) Delinquent behavior is learned.

2) Learning is by product of interaction. Thus delinquency cannot occur without the aid of others; it is a function of socialization.

3) Learning occurs within intimate groups.

4) Criminal techniques are learned.

5) Perception of legal code influence and drives. The reaction to social rules and law is not uniform across society, and children constantly come into contact with others who maintain different views on the utility of obeying the legal code. Some kids, they admire may openly disdain or flout the law or ignore its substance. Kids experience what Sutherland called "culture conflict" when they are exposed to different and opposing attitudes toward what is right and wrong or moral and immoral. The conflict of social attitude and cultural norms is the basis for the concept of differential association.

6) The differential association may vary in duration, frequency, priority, and intensity. Whether a person learns to obey the law or to disregard it is influenced by the quality of social interaction. Those of lasting duration have greater influence than those that are brief. Similarly, frequent contacts have greater effect than rare and haphazard contacts. Sutherland did not specify what he meant by priority, but Cressey and others have interpreted the term to mean the age of children when they first encounter definitions of criminality.

Finally, intensity is generally interpreted to mean the importance and prestige attributed to the individual or groups from whom the definitions are learned. The influence of the father, mother, or trusted friend far outweighs the effect of more socially distant figures (Sigel and Welsh, 2012: pp. 156-157).

Additionally, the basic Idea which will be discussed in this paper, according to Sigel and Welsh, 2012 is "the more deviant and adolescent social network and network of affiliation, including parents, peers, and romantic partners, the more likely they are to engage in antisocial behavior" (p. 158).

Moreover, differential association theory is the best theory to test the hypothesis of this paper, for two reasons; can be tested and based on evidence. Differential association theory has a clear concept and it is easy to understand and test. Williams and McShane, 2013 stated: "good theory is logically constructed, is based on the evidence at hand, and is supported by subsequent research. Empirical evidence should not be confused with personal ideology, such as religious sentiments or political leaning, or even with what some authority figure tells us" (p.6). In addition, good theory allows us to understand and explain the different facts of the surrounding environmental situation, according to Sigel and Welsh, 2012 "he used the term 'differential social organization' or 'differential group disorganization' instead. This allowed him to more clearly apply the learning process to a boarder range of American society" (p. 69).

Also, the selected theory is the best theory to test the issue a researcher had chosen, because it is the only theory that explains the criminal behavior based on the social interaction not on the biological or mental issues. The ideas of this 
theory are simple and understood, also. According to Williams and McShane, 2013: "Sutherland provided less complex and more coherent approach to the cause of crime and delinquency. Yet his ideas were well grounded in existing evidence" (p. 64).

\section{Empirical Research Literature Review}

This research paper will test the hypothesis that states delinquent behavior is learned and attached by a criminal parent or criminal peer groups. This point from the concepts of differential association theory, and there are several studies that have examined this relation.

One study shows how peer delinquency and substance use were related to transitioning between abstaining, delinquency, substance use, and co-occurring problem behavior (Monahan, Rhea, Hawkins, \& Brown, 2014). The study found that the effect of peer groups on criminal behavior is domain specific, when individuals transition from abstaining to a single problem behavior, but are more general with respect to escalation of desistance from problem behavior (Monahan et al., 2014). The study examined the hypothesis by using the survey to collect the data from students who are in sixth to tenth grade (Monahan et al., 2014). The study also found that once youth are involved in either delinquency or substance use, they appear to be more vulnerable to co-occurring criminal behavior when exposed to any peers who engage in these criminal behaviors. Finally, once the person begins to commit criminal behavior within peer groups, criminal behavior is highly likely to continue (Monahan et al., 2014).

Another study tests the effect of peer groups among adolescence and low-parents monitoring (Barnes, Hoffman, Welte, Farrell, \& Dontcheff, 2006). The study indicates that during adolescence, peer groups have increasingly important effects on adolescent behaviors especially with the low parent's supervision (Barnes et al., 2006). By using quantitative methods, study found that an association with deviant peers is a significant risk factor for alcohol use, drug use, and delinquency; even after taking into account socio-demographic, individual, and parenting factors (Barnes et al., 2006).

The next study presents how the poverty, neighborhood SES, parental pressure and mastery, self-control, and parental negative behavior could affect the child's behavior by using the data from the Fragile Families Study, Samples, interviews, and journalism (Church, Jaggers, \& Taylor, 2012). Social control and differential association theory were the frameworks for this study. The study examined individual choices and the effect of the environment. The study assumed that there is a direct link between living in poor neighborhood, family stress and children negative behavior (Church et al., 2012). The study focused on the children's negative behavior because the juvenile delinquency studies have approved that initial negative conduct in kids leads to increased possibility of teenage crime performance. The study also expected that there is a connection between negative behavior and family and neighborhood factors, such as family strength, poverty (Church et al., 2012). The study found that beside the parental 
negative behavior influence, there is the influence of the neighborhood and the environment. The study found that there are linkages between the neighborhood SES and aggravation in parenting and negative conduct. These relations would imply that the worse the neighborhood that a family exists in, the more likely the family will experience pressure and bad conduct (Church et al., 2012).

Another study displayed that association with criminal peer groups could affect the relative stability of self-control; and the individual's decision to engage the crime is depending upon the level of self-control. Also, individuals with low self-control incline to interact with the individuals similar to them, they have a weak personality, and they are committing the crime simply (Jennings, Higgins, Akers, Khey, \& Dobrow, 2013). The study assumed that stability of self-control could be influenced by associating with delinquent peers (Jennings et al., 2013). The data for the study was collected by using longitudinal sample. This data was collected from 1998 through 2006. Finally, the study found the relationship between delinquent peers could affect the levels of self-control, especially the individuals who have low self-control (Jennings et al., 2013).

One study shows the effect of broken homes and attachment to parents and peer learning by definition of delinquency among different races, based on the conceptions of differential association and control theories (Matsueda \& Heimer, 1987). The study hypothesized that Blacks and Non-Blacks who live in troubled neighborhood, broken homes, and lack of parental supervision have direct delinquency influence, and this influence is greater among Black more than Non-Black, these variables including the age, have larger effect because they represent an important source of definitions of delinquency (Matsueda \& Heimer, 1987). By using quantities methods, the study found offender's friends who lack of parental supervision expert a direct effect of the definitions of delinquency. The effect of bad neighborhoods is greater for those who live in broken homes with lack of supervision (Matsueda \& Heimer, 1987). In addition, being older from a broken home or a troubled neighborhood could increase the chance of delinquency. This happened in weak attachment to parents and peer groups growing the number of criminal friends and decreasing the conformist attitudes (Matsueda \& Heimer, 1987).

One study of differential association group and solo offending tests the influence of delinquent friends' behaviors and attitudes in general, group, and unaccompanied offending for crimes vandalism, theft, and assault (Hochstetler, Cops, \& DeLisi, 2002). The study examined whether a group's attitudes and behaviors are only important when friends are present (Hochstetler et al., 2002). Data for this study was collected from children between the ages of eleven and seventeen to examine the effect of differential association of crime committed alone and in group (Hochstetler et al., 2002). The study found both friend's attitudes and behaviors affect the offending by means other than the influence on respondent attitudes. Both friend's attitudes and behaviors maintained significant effects on solo offending controlling for own attitudes (Hochstetler et al., 2002). In conclusion study suggests that there are significant effects for friends' 
influences in the solo equalities implied that crime is learned by transference of some so (Hochstetler et al., 2002).

The next study examined the relationship between delinquent peers and delinquent behavior (Matsueda \& Anderson, 1998). The study hypothesized that delinquency is caused by delinquent peers as well as association with delinquent peers are caused by previous delinquent behavior, and delinquent peer association increases the likelihood of future delinquent behavior (Matsueda \& Anderson, 1998). By using data from the National Youth Survey and estimate a cross-lagged panel model, and longitudinal data on a representative sample of a heterogeneous population of adolescents; study found that there is a strong correlation between delinquent peer associations and delinquent behavior. The study also found that delinquent's behavior exerts a large effect on delinquent peer's association. Moreover, the effect of delinquency on delinquent peers is larger than the effect of delinquent peers on delinquency (Matsueda \& Anderson, 1998). The results suggest that delinquent peer's association and delinquent behavior are reciprocally related, but the effect of delinquency on peer associations is larger than that of peer associations on delinquency (Matsueda \& Anderson, 1998).

Finally, the last study used the generality of social control and differential association theories to test felony offender among both genders (Alarid, Burton, \& Cullen, 2000). The study used the sample of both gender delinquents who drawn from the city center to examine both overall offending and involving specific kind of crime. The study also tests the influence of parent and friend's attachment on the criminal (Alarid et al., 2000). Data for this study was collected by self-report surveys, from people between seventeenth and eighteenth (Alarid et al., 2000). The study found that the teens who have a strong relationship with their parents are less involved in the crime, and the effect of the involvement in crime was similar for both genders, but men have a greater chance to involve the crime if they attached with criminal peers (Alarid et al., 2000).

\section{Hypothesis}

Based on the review, the proposed study hypothesis is that there is a linkage between having deviant parents and becoming a criminal as well as having deviant friends and becoming a criminal. Need it now, is research that examines the relation associated with deviant parents or friends, and becoming a criminal.

\section{Operational Definitions of Research}

1) Adolescent: a young person who is in the process of growing from childhood to adulthood between the age of 12 and 17 .

2) Antisocial behavior: Any action or behavior that could harm a person or himself rather than society; usually breaks the rules of society such as smoking.

3) Criminal behavior: Any behavior that is considered illegal and would harm the person himself, society, and break the law such as drug use and theft. 
4) Deviant: $\mathrm{He} / \mathrm{she}$ does something unusual or unacceptable.

5) Network of affiliation: The connection, attachment, or relationship between friends, family, or classmates.

6) Parents: They are male and female who are related by marriage or partnership.

7) Peer groups: Intimate friends who usually live in the same neighborhood, study in the same school, or could be relatives.

8) Social network: Any connection between individuals who usually live in the same geographical area and have the same customs and backgrounds.

\section{Methodology}

In this research paper, the researcher used a qualitative approach which is data collected on the juvenile delinquency topic. The researcher proposed this approach to examine the linkage associated with deviant parents or friends and becoming a criminal.

\section{Data Analysis}

The hypothesis for this research proposed that there is a relation between deviant parents or peer groups and criminal behavior. Based on what has been done prior to the empirical research review, the researcher could state that there is a strong relation between these variables. Significantly, peer groups have a strong influence on the person during adolescence, especially those who have a low self-control and fragile personality. In other words, deviant peer groups will not affect the teenager who has a strong support system and high self-confidence. On the other hand, the researcher assumed that unlike the person who commits the crime individually, the person who committed the crime deviant peer groups would probably have thoughts and attitudes that have been influenced. Also, the person who commits the crime with his friends has the likelihood to do the crime individually. One study found there is a strong correlation between delinquent peers and delinquent behavior. The study found that the effect of delinquency on peer's association is greater than that peer's association on delinquency (Matsueda \& Anderson, 1998). This idea is like asking the question of who came first, the chicken or the egg.

\section{Conclusion}

Significantly, any issues cannot be explained with one reason or solved with one treatment; this situation of complication is similar to the research topic. In this paper, the researcher finds that the effect of deviant peer groups and deviant parent during adolescence is quite similar. Both peer groups and parents have an important position in the teenager's life.

Thus, any solution should indicate these two important variables. Beside the effect of deviant peer groups and parents, the researcher also found that bad neighborhoods, fragile personality, and poverty play critical roles in delinquen- 
cy. Indeed, to solve this problem, it is necessary to start from the main stages like the family (socialization), and the school (education). In addition, the study's suggestions will be based on the research findings. There are several ways to reduce or prevent juvenile delinquency. Starting with family, parents have main roles to prevent juvenile delinquency. Before all, parents should know that they are responsible for their children, and they have the right to protect them. Parents should control their children by asking them about their friends and how they usually spend their time away from home. Also, parents should be friendly and open-minded with their children, giving them attention and understand them. On the other hand, deviant parents should seek help to be role-models for their children. Big sisters and brothers also have positive roles as well as the parents' roles. For instance, in Saudi Arabia parents believe in raising the older brother or sister to be a role-model to the younger. After all, schools have basic rules to prevent or reduce delinquency. Since the researcher clarifies that the influence of deviant peer groups is greater in bad neighborhoods and poverty; thus the researcher will target those who live in slums and poverty and they cannot afford the price of after school programs or activity classes. Research suggests that poor teenagers should be allowed to join after school programs for free. The community should also allow summer programs, support small projects, or encourage the teenagers to volunteer. Finally, as individuals we should stand hand in hand to protect our family and reduce juvenile delinquency.

\section{Conflicts of Interest}

The author declares no conflicts of interest regarding the publication of this paper.

\section{References}

Alarid, L. F., Burton, V. S., \& Cullen, F. T. (2000). Gender and Crime among Felony Offenders: Assessing the Generality of Social Control and Differential Association Theories. Journal of Research in Crime and Delinquency, 37, 171-199. https://doi.org/10.1177/0022427800037002002

Barnes, G. M., Hoffman, J. H., Welte, J. W., Farrell, M. P., \& Dintcheff, B. A. (2006). Effects of Parental Monitoring and Peer Deviance on Substance Use and Delinquency. Journal of Marriage \& Family, 68, 1084-1104. https://doi.org/10.1111/j.1741-3737.2006.00315.x

Church, W. T., Jaggers, J. W., \& Taylor, J. K. (2012). Neighborhood, Poverty, and Negative Behavior: An Examination of Differential Association and Social Control Theory. Children and Youth Services Review, 34, 1035-1041. https://doi.org/10.1016/j.childyouth.2012.02.005

Hochstetler, A., Copes, H., \& DeLisi, M. (2002). Differential Association in Group and Solo Offending. Journal of Criminal Justice, 30, 559-566. https://doi.org/10.1016/S0047-2352(02)00177-0

Jennings, W. G., Higgins, G. E., Akers, R. L., Khey, D. N., \& Dobrow, J. (2013). Examining the Influence of Delinquent Peer Association on the Stability of Self-Control in Late Childhood and Early Adolescence: Toward an Integrated Theoretical Model. Deviant Behavior, 34, 407-422. https://doi.org/10.1080/01639625.2012.735903 
Matsueda, R. L., \& Anderson, K. (1998). The Dynamics of Delinquent Peers and Delinquent Behavior. Criminology, 36, 269-308.

https://doi.org/10.1111/j.1745-9125.1998.tb01249.x

Matsueda, R. L., \& Heimer, K. (1987). Race, Family Structure, and Delinquency: A Test of Differential Association and Social Control Theories. American Sociological Review, 52, 826-840. https://doi.org/10.2307/2095837

Monahan, K. C., Rhew, I. C., Hawkins, J. D., \& Brown, E. C. (2014). Adolescent Pathways to Co-Occurring Problem Behavior: The Effects of Peer Delinquency and Peer Substance Use. Journal of Research on Adolescence, 24, 630-645. https://doi.org/10.1111/jora.12053

Sigel, L. J., \& Welsh, B. C. (2012). Juvenile Delinquency: Theory, Practice, and Law (12th ed.). Cengage Learning.

Williams, F. P., \& McShane, M. D. (2013). Criminological Theory(6th ed.). Pearson. 